\title{
Establishment of an American Branch-Campus Model of Higher Education: Qatar's Early Goals, Rationales, and Challenges
}

\author{
By Pamela Walsh
}

\begin{abstract}
This study presents original research findings of a qualitative study of Qatar's international higher-education branch-campus model, which in 2016 hosted 11 international branch campuses, among the most of any country then. Few studies have examined the rationales, goals, and challenges of the branch-campus model from a host country's perspective. This paper asks two central questions: 1) Why did Qatar partner with six North American universities to establish six international branch campuses between 2001 and 2008 and 2) what were the challenges during the early years of operations from the Qatari and branchcampus leadership perspectives? This study's primary data-collection method was face-toface, open-ended interviews. I interviewed 18 participants in Qatar and recruited based on potential participants' positions relative to the establishment, oversight, and governance of the six branch campuses. I also included executives and directors from the government of Qatar, Qatar Foundation, and leadership of the six branch campuses. I used extant documents, such as annual reports, strategic plans, government reports, speeches, and popular-media articles as additional data sources. Findings included rationales and goals related to pedagogy, sociocultural development, societal engagement, development of research capacity, and Qatar's status as a leader and driver of change in the Arab Gulf region and beyond. Challenges included sociocultural issues, tensions between the international branch-campus leaderships and their home institutions, and conflicting expectations between the branch campuses and Qatar Foundation. These findings include in-depth and new insights into host-country goals and aspirations, and challenges experienced by U.S. and host-country partners, and how these challenges have been addressed.
\end{abstract}

Keywords: American Branch-Campus model, Education City, International branch campus, Qatar Foundation, Transnational Higher Education.

\section{Introduction}

Internationalization of higher education, an increasingly common theme in higher-education literature of the last decades, may be defined as the integration of "an international, intercultural or global dimension into the purpose, functions, and delivery of post-secondary education, in order to enhance the quality of education and research ... and to make a meaningful contribution to society" (de Wit \& Hunter, 2015, p. 3).

Transnational initiatives include the movement of individuals, educational programs, and institutions across national borders (Knight \& Liu, 2017; Mazzarol, Soutar, \& Seng, 2003). Transnational education and the associated literature have

\footnotetext{
*Associate Professor, University of Athabasca, Canada.
} 
grown significantly in the last 15 years and are influenced by globalization, university and country quests for institutional prestige, and governments' declining financial support for higher education.

The least common form of transnational education is the international branch campus (IBC), but IBCs have grown rapidly since 2000 (Altbach, 2011; Garrett, Kinser, Lane, \& Merola, 2016; Knight \& Liu, 2017). An educational institution that establishes an IBC in another country is, interchangeably, the sending, parent, or home institution. The foreign country that hosts an IBC is known as the host country.

IBC models and relationships between IBCs and host countries vary from country to country (Crist, 2015; Garrett, 2018; Kinser \& Lane, 2016; Borgos, 2016). Host countries generally engage with their IBCs (Garrett, 2018; Kinser \& Lane, 2016) and often with their IBCs' parent institutions. Prestigious universities may receive generous IBC funding from host countries or other entities while home universities typically provide little, if any, up-front investment (Altbach, 2011, p. 5). For example, IBCs in the Arab Gulf region and their parent institutions receive significant subsidies and other incentives (Altbach, 2011; Crist, 2015).

The two leading IBC authorities, the Observatory on Higher Education, which has produced comprehensive reports on IBCs since 2011, and the Cross-Border Education Research Team, produced a 2017 report (Garrett, Kinser, Lane, \& Merola, 2017) that noted 263 existing IBCs and 20 under development. The United States was identified as the top sending country, and China as the top host country, followed by the United Arab Emirates (UAE), Malaysia, Qatar, and Singapore.

IBC research has grown over the last 20 years. A recent review and analysis of about 300 journal articles and other scholarly literature on cross-border internationalization initiatives revealed that research has focused more on IBCs than on transnational-education modes (Knight \& Liu, 2017). This research, however, has been written predominately from sending-institution perspectives, while "research from the host-country perspective is significantly underrepresented" (Knight \& Liu, 2017, p. 15), indicating a significant gap in the literature.

This paper presents original qualitative research findings of six IBCs in Qatar: Virginia Commonwealth, Cornell, Carnegie Mellon, Texas A\&M, Georgetown, and Northwestern (Walsh, 2011). These six prestigious American research universities were all still operating as of October 2018 and were each formed between 2001 and 2008 as part of Education City, Qatar's higher-education infrastructure, which was established in the late 1990s.

Qatar has invested significant financial and nonfinancial resources into all its IBCs, especially IBCs in Education City, yet little, if any, research addresses Qatar's early rationales and motives for establishing an American branch-campus model. Additionally, only limited research focuses on early host-country challenges, including Qatar's.

The following constitutes this study's two research questions:

1. Why initially did Qatar partner with six North American universities to establish six international branch campuses between 2001 and 2008? and 
2. What were the challenges, from Qatar and branch-campus leadership perspectives, during the early years of operations?

\section{Study Context}

Qatar is a small wealthy Arab state headed by an emir, located on the Arabian Peninsula, and ruled by the Al Thani family since the mid-1800s. The Qatar people are believed to be descendants of ancient Arabian tribes who migrated to the peninsula between the 17 th and early $19^{\text {th }}$ centuries CE. Qatar signed an agreement with the British government in 1868 establishing Qatar as a country under British protection (Toth, 1994; Zahlan, 1979), and it continued as a British protectorate until 1971 (Zahlan, 1979). Oil discovered in Qatar in 1939 has, since the 1950s, brought increasing oil revenues, prosperity, and social progress (Zahlan, 1979).

Over the last 70 years, Qatar transformed itself from a relatively poor British protectorate into an independent state with one of the largest natural-gas reserves in the world. Hamad bin Khalifa Al Thani, Emir of Qatar from 1995 to 2013, is widely acknowledged as having led unparalleled economic investment and political and media reforms. Qatar has shared its wealth, generously, with Qatari nationals, who operate in a welfare system ensuring their continued financial comfort. Nationals prefer to work in government enterprises, which have better working conditions, salary, benefits, and job security than the private sector. According to a Rand-Qatar Policy Institute report prepared for the Supreme Education Council of Qatar, 77\% of employed Qataris were working for government enterprises in 2004 (Stasz, Eide, \& Martorell, 2007, p. xiii).

The discovery of oil in Qatar created employment for many expatriates in the otherwise labour-deficient Gulf state region. This labour influx has spurred rapid development but impacted the economy, politics, and the social structure in unforeseen ways (Jureidini, 2014). Qatar's population was 1.6 million in 2009, the year this article's original research was conducted, and 2.7 million in 2018 (Government of Qatar, Ministry of Development Planning and Statistics, 2018). Qatari nationals make up less than 15\% of Qatar's population ("Qatar Population 2018," 2018). Qatar's planning documents, especially its national-vision document, Qatar National Vision 2030, reflect concerns about this significant demographic imbalance (Government of Qatar, General Secretariat for Development Planning, 2008, p. 3).

Unlike some of its neighbours, Qatar has been politically stable and had little political unrest. The country has played a regionally diplomatic role as a mediator of regional conflicts. The former emir promoted Qatar's international position and ambitious regional engagement. The country's policies, actions, and interventions, however, have not always been popular with neighbours like Saudi Arabia, the UAE, and Bahrain (Middle East Institute, n.d.).

Kelly criticized the Gulf States for their poor defense of civil rights and women's personal status and autonomy. She reported "positive change has come [in Qatar and the UAE] as the result of an increased political will to engage on the 
issue of women's rights, as well as advocacy by powerful, well-connected women such as Sheikha Moza," wife of the former emir, as well as Hamad bin Khalifa Al Thani and an unacknowledged leader of education and other social reforms in the country (Kelly, 2014, para. 4). Women from Qatar and the UAE have, however, made progress in education, creating study opportunities in STEM fields (Kelly, 2014, p.4). With the establishment of Qatar Foundation for Science, Technology, and Community Development (QF) in 1995, ongoing higher-educational reforms have focused on Qatar's national university, Qatar University, and Education City.

From 2001 to 2008, Education City established six IBCs in partnership with six U.S. parent universities. As of January 2017, the U.S. Education City branch campuses were Virginia Commonwealth University in Qatar (established 1998 and became an IBC in 2001); Weill Cornell Medicine-Qatar (established 2001); Texas A\&M University at Qatar (established 2003); Carnegie Mellon University Qatar (established 2004); Georgetown University in Qatar (established 2005); and Northwestern University in Qatar (established 2008). Moza bint Nasser, QF chairperson and cofounder and UNESCO Special Envoy for Basic and Higher Education, affirmed that Qatar and QF chose universities based on the prestigious programs they offered: "We have brought to Qatar leading degree programs in engineering, business administration, computer science, design, foreign service, and medicine - all disciplines that are critical to our ability to sustain the many advances we are making" (Sidra Medical Research Center, 2010, para. 2). QF further founded Hammond in 2010 as the "flagship national university" in Education City (Hamad Bin Khalifa University, n.d., para. 6). Hamad Bin Khalifa University is a "homegrown research and graduate studies University that acts as a catalyst for positive transformation in Qatar and the region" (Hamad Bin Khalifa University, n.d., para. 1); however, no other U.S.-based Education City IBC has been established since 2010 .

As of July 2010, 575 students had graduated from five of the six American IBCs in Qatar. Northwestern University in Qatar graduated its first class in May 2012. The number of graduates from these and other IBCs increased steadily from 2010 to 2015 (Government of Qatar, Ministry of Development Planning and Statistics, 2017a, p. 50). QF hailed Education City as "a unique ecosystem of academic excellence" and a pioneer in its approach to global education (QF, n.d.-a, para. 1). At the behest of QF, the six U.S. IBCs have held joint convocation ceremonies and cross-registered students from all six IBCs and participated in other joint initiatives. Crist (2015) stated that Qatar's Education City is an "unprecedented development in the field of IBCs and global education . . . and a new organizational form" (p. 92). Walsh (2011) referred to Qatar's six U.S. IBCs and one Canadian IBC as a "North American branch campus model of higher education" (p. 94).

Qatar financed U.S. universities that set up these branch campuses: Through $\mathrm{QF}$, it paid for facilities, operations, staff, travel, relocation, and other costs. In addition, QF paid each institution a management fee for operating a branch campus in Qatar. QF negotiated eligible expenses and management fees separately with each institution. Qatar Authority, a government committee, made the same arrangements with two Canadian institutions not in Education City: the College of 
the North Atlantic and the University of Calgary. The terms of these agreements guard the contractual details between QF and each U.S. university; however, each American Education City institution has generated significant profits from these partnerships (confidential personal communication, April 10, 2009). Qatar further covered the tuition of many Qatari students attending branch campuses, while other students were supported by scholarships or companies they work for. QF offers merit-based scholarships to high-achieving applicants each year and interest-free loans to qualified international students and non-Qatari residents. The number of students enrolled in Qatar universities increased from 6,000 students to 28,000 in the 25 years leading up to 2014-2015, while the percentage of university-enrolled Qataris in terms of total enrollment reached 62\% the same year (Government of Qatar, Ministry of Development Planning and Statistics, 2017a, p. 48).

Since 2006, QF has vigorously pursued research missions with its Research, Development, and Innovation division and in alignment with the "nation's goal of building a sustainable and diversified economy" (Qatar Ministry of Transport and Communications, n.d., para. 2). QF established the Qatar National Research Fund in 2006 as part of QF's ongoing commitment to establishing the country as having a knowledge-based economy. An initiative of QF, Qatar Science and Technology Park located in Education City was inaugurated in 2009 as Qatar's hub for applied research, technological innovation, incubation, and entrepreneurship (Qatar Ministry of Transportation and Communications, n.d.).

\section{Literature Review}

\section{Host-Country Rationales and Goals}

This literature review focuses on peer-reviewed studies analyzing goals and rationales of host countries that supported the establishment and development of higher-education institutions' IBCs in their jurisdictions. As indicated, a gap exists in the literature regarding host-country rationales and goals.

Becker (2009) looked at potential benefits to host countries with established branch campuses. These benefits include host-country rationales and motives and the bolstering of the national higher-education system's prestige through possession of world-class foreign university host campuses (p. 5). Lane (2011b) also suggested that host countries wish to enhance their reputations. Similarly, Buckner (2011) stated that while some of these countries seem interested in higher-education reforms, the "expensive, private American-style universities' primary role in [Arab] Gulf states ... is to bring prestige ... to the Gulf states" (p. 25). Buckner notes the difficulty of determining the "real motivations of Gulf policymakers" and found little research indicating factors shaping nations' highereducation policies in the Middle East and North Africa. Several studies referenced economic rationales that included the following needs and aspirations. 
- "income generation to local economies from students throughout the region,"; highly skilled workers and foreign students who will work locally after graduation; and opportunities for Qataris to obtain foreign degrees at home (Becker, 2009, p. 5),

- modernization of the national economy (Lane, 2011b), and support for a workforce required for future economic development (Borgos, 2016; Crist, 2015; Lane 2011b),

- global marketplace participation (Borgos, 2016, p. 285), and

- the creation of a knowledge economy (Crist, 2015) through initiatives like research and development (Crist, 2017a; Garrett, Kinser, Lane \& Merola, 2017), a rationale that has not received in-depth analysis in the literature.

The literature referenced some host countries' intent to improve highereducation capacity, including diversification of domestically offered programs, availability of pedagogies different than the host country's (Lane, 2011a), and the transfer of locally adaptable research, teaching, quality assurance, and administration models (Becker, 2009, p. 5). Borgos (2016) examined organizational models of U.S.-established IBCs in China, Qatar, and the UAE and concluded that differences between the three models can be linked to each country's "historical developments respective of national strategies" aimed at increasing educational capacities (p. 285). Similarly, studies have linked IBC development to host countries' overall higher-education strategies (Becker, 2009; Crist, 2015; Lane, 2011a). Lane and Kinser (2011) reported that the Qatar, Sarawak, and Malaysia governments used foreign higher-education providers to support public goals, such as local capacity building.

Crist (2015) stated that combined factors, like wealth, poor national education systems performance, and labor shortages, spurred the implement-tation of "bold" strategies, like the establishment of university IBCs in the UAE, Saudi Arabia, Qatar, and Bahrain (p. 94).

\section{International Branch Campuses: Risks and Challenges}

The literature identified financial, political, regulatory, reputational, academic, managerial, and cultural risks to parent institutions and IBCs. Compared to other kinds of educational partnerships, IBCs are thought to pose the most significant risks to both sending institutions and host countries. Financial losses incurred by parent institutions, reputational issues, and branch closures constitute risks to branch-campus operations (Altbach, 2011; Becker, 2009; Borgos, 2016; Wilkins, 2016). Risks can arise from changes in the political environment or regulatory framework, increasing political or social uncertainty, and host-country safety issues, such as those associated with the Arab Spring (Altbach, 2011). The economic and diplomatic embargo of Qatar, for example, could have negative impacts for IBC students and staff in Qatar (Redden, 2017). Other risks could arise from host countries' curtailments of academic freedom (Kinser \& Lane, 2016, p. $5)$. 
IBC failure can constitute significant financial and reputational risks to home institutions. When a Canadian college opened a Saudi Arabia campus in 2013 in partnership with Colleges of Excellence, a private entity contracted to run the program on behalf of the Saudi government, critics within the parent college publicly expressed concerns about the Gulf country's human rights record. Several years later, after significant financial losses, the college announced both its withdrawal from its five-year contract (Fagan, 2017) and a final settlement agreement with Saudi Arabia (Algonquin College, 2017, p.3). Similarly, in 2009, George Mason University - one of the first American universities to open an IBC in the UAE, itself the second largest host country in the world (Garrett et al., 2016) — closed its IBC after only four years of operation. GMU's IBC's challenges included recurrent leadership turnover, difficulty recruiting academically qualified students (especially in terms of language proficiency), and few faculty members from the parent university in Virginia (Mills, 2008, para. 4).

Some IBC partnerships pose a minimal financial risk to sending institutionsfor example, as a host country, Qatar bears all costs associated with its six U.S. IBCs, including parent U.S. universities' costs of supporting overseas branch campuses, such as costs associated with hiring additional at-home staff to support IBCs in Qatar.

Cultural challenges to parent institutions and IBCs include that expatriate employees must adapt to host-country norms, customs, religious practices, and holidays. For example, the non-Muslim staff at Muslim-country IBCs might have to avoid public eating or drinking on IBC grounds during Ramadan when Muslim students and staff are fasting. Cultural taboos include male-female relationships between students and between unmarried people (Lane, 2011a).

Recruiting qualified students, faculty, and leadership to IBCs has been difficult (Altbach, 2011; Healey, 2016). IBC-appointed managers may have difficulty dealing with faculty unfamiliar with host-country culture or who are sent from parent institutions for brief periods to teach or provide oversight of newly established programs (Smith, 2014). Seconded staff face the additional challenge of serving two entities, the parent institution and its IBC (Chapman, Austin, Farah, Wilson, \& Ridge, 2014; Smith, 2014). For example, conflicting expectations of faculty members may exist between a home-institution dean and an onsite IBC manager. Also, because faculty members may not want to teach overseas if doing so interrupts their research agendas (something IBCs might not have the capacity to sustain), long-term recruitment of faculty from home institutions to IBCs can be difficult (Altbach, 2010; Healey, 2016).

IBC managers work with distinct employee groups with different homeuniversity affiliations, durations of stay, and compensation packages (Healy, 2016; Hughes; 2011). Locally hired IBC staff received the lowest wages and least generous terms and conditions and had the highest turnover rates. Healy (2016) looked at IBC-management challenges as perceived by IBC managers in nine U.K. university IBCs, including IBCs in the UAE and China (p. 64). Most of the nine interviewed managers were seconded from home universities, only a few had previous management experience, and the selection for each of them was informal or pro forma. It is noted that inexperienced managers may increase IBC risk (p. 
72). All managers in Healey's study identified that their home institution lacked understanding of IBC realities and challenges. Managers also cited difficulties interpreting agendas and objectives of multiple stakeholders, including those of students, host governments, local players, and parent institutions with diverse actors, such as presidents and provosts (Healey, 2016).

The scholarly literature reviewed here does not reveal IBC operational challenges from host-country perspectives.

\section{Methodology}

This study utilized a qualitative methodology to explore Qatar's early rationales and goals for establishing six American university IBCs in Education City. It also explored challenges encountered by IBCs and QF during the six campuses' early years of operations. I used open-ended, in-depth interviewing strategies to gather data and existing documents for additional data. Because document analysis is frequently combined with interviews and other qualitative research methods to triangulate and corroborate findings (Bowen, 2009), I examined the Government of Qatar, QF, and IBC reports and speeches. Some of these documents provided additional context, and information participants may have forgotten, did not have access to, or that predated participants' involvement in planning and implementing events related to the six branch campuses.

\section{Participants and Interviews}

I submitted the proposed study to the University of Calgary's required research-ethics review process and followed the approved ethics protocol. The participants I selected were leaders in positions relative to the U.S. branch-campus model in Qatar in at least one of the following capacities: planning, implementation, oversight, and management. Informed by recommendations from influential Qatar and QF insiders, I included parent university-appointed executives and directors within the Government of Qatar and QF and those persons with senior IBC positions. Most participants were connected to the IBC model for at least five years.

After an initial telephone or email contact but in advance of the interview, I provided most participants with detailed information and a consent form explaining the study's purpose and the participant's role in the study. To participants whose email addresses I did not have, I provided this form at the interview.

Sixteen of the 18 interviews took place at participants' workplaces in Qatar, most of which were located within QF or government offices. Two interviews were conducted offsite in Qatar. All 18 interviews were conducted in English. I designed an interview guide to address my research questions. While I used a common set of questions with all participants, the open-ended nature of the interviews allowed me to ask new questions and seek deeper understanding as interviews unfolded. Key interview questions included the following. Explain why 
Qatar was interested in partnering with universities from the United States? What did you hope to achieve?

Why not focus your resources on reforming the national university? What challenges have you experienced along the way?

\section{Data Analysis: Interviews}

I used a qualitative analytic data-examining process to seek answers to the research questions. As part of this process, I scanned the primary data to determine the words and phrases most commonly used by respondents. I manually categorized these words and phrases into codes with meaningful titles such as "critical thinking" and "rote memorization." I organized the codes into like categories, such as "teaching and learning," and then searched for relationships and themes within and among the categories, such as "preference for Western pedagogy." I then further analyzed the themes to draw conclusions and arrive at findings I could present.

\section{Document Analysis}

Before and after the interviews took place, I reviewed approximately 40 documents for data regarding Qatar rationales and goals for partnering with six American universities to establish IBCs in Qatar. Approximately 25 of these documents were utilized in this study. These include annual reports, government planning documents, newspaper articles, and speeches, most of which dated from between 1998 and 2010 and which covered IBC planning and early operations. To review these documents, I used an analytic process much like I used in my interview analysis including codification, categorization, organization, and identification of major themes. This process allowed me to uncover information, develop understanding, and discover insights relevant to the first research question and informed my interview questions. I triangulated emergent themes from my interview-data analysis with themes emergent from my document analysis. These themes were similar and often complementary-interview data, for example, sometimes provided additional context for information uncovered through document analysis. The reverse was also sometimes true.

\section{Findings}

\section{Rationales and Motives: Participant Interviews and Document Analysis}

Five themes emerged relative to my first research question (Why did Qatar partner with six North American universities to establish six international branch campuses between 2001 and 2008?) emerged from my participant-interview data analysis and extant documents. This section includes participant responses and excerpts from the documents. The rationales emergent from my interview analysis and those emergent from my document analysis broadly agree. 
Meet Qatar's Need for a Quality Higher-Education System That Fosters Critical Thinking and System-Wide Reforms. All participants indicated that one of Qatar's goals was the introduction of high-quality North American education and pedagogy, including the fostering of critical thinking and student leadership. Qatari participants stressed that past efforts to reform the national education system from within were unsuccessful. Participant A explained that the branch campus was "mandated to bring a Western-style education to Qatar," including a learning culture consisting of critical thinking, problem-solving, and student leadership. Participant $\mathrm{C}$ noted that changing from within is difficult and rarely works, especially when people are "set in their ways and highly resistant to change." Document analysis supported these findings. Nasser said, "Qatar is determined and committed to reconsidering archaic methods of education in order to better meet the needs of our changing society" (Al-Misnad, Bint Nasser, 2004, p. 82).

Provide Quality Education from Prestigious Universities within the Country in a Culturally Appropriate Environment. Most Qatari and non-Qatari participants identified access to quality education within a culturally appropriate Qatar environment as a rationale for the branch-campus model. Qatar government, QF, and branch-campus participants spoke about factors preventing students from accessing an education outside the country. While many Qatari nationals can receive full financial support for education abroad, others face barriers, such as those related to gender: some families do not allow women and girls to travel overseas unless accompanied by a close male relative; others may be restricted by family responsibilities preventing them from studying abroad. Participant B explained that the branch model provides Qataris opportunities "to attend excellent universities without the cultural issues, complexities, and trauma of going abroad." This rationale was not explicitly apparent in the documents I reviewed and analyzed.

Prepare Qatar to Participate in a Global Knowledge Society through Development of Its Human Resources and Its Capacity for Research and Development. Qatari and non-Qatari participants talked about the importance of building local capacity and developing and diversifying a Qatari workforce through quality education and training. Qatari participants emphasized the importance of preparing individuals for the knowledge economy: "The goals for the branch campus include building human capital amongst our people, not only for today's needs but also for post-oil and gas, and to help build an understanding of the value of work. In time, the graduates themselves will be catalysts for change" (Participant Q).

Most participants referred to Qatar's aim to develop both the country's research capacity and the roles that branch-campus universities, faculty members, and research institutions play in this capacity. Participant $G$ explained that the expectation for faculty to do research is growing and "we are making some important advances here." Participant D stated that to build Qatar research capacity "we must have the top universities in Qatar." Participant P emphasized that $\geq$ the 
emir has dedicated the revenues from one oil well to support research in Qatar [thereby] turning energy into knowledge!"

This theme also emerged during my review and analysis of annual reports, including of Georgetown University School of Foreign Service (2007-2008), Weill Cornell Medical College (2010), and Qatar Foundation (2011).

Promote Societal Engagement and Sociocultural Development. Qatar participants, directly and indirectly, spoke about Qatar's need for social and cultural change but emphasized that this change must maintain core cultural values. Such changes include "emancipation of women, changing the culture of entitlement, and transforming the society" through societal engagement (Participant P). Participants spoke about the role of the American IBCs in facilitating change. Participant $\mathrm{C}$ stated that while change does not happen overnight, over time "a critical mass of [IBC] graduates can push for [societal] change."

To Enhance the Country's Status as a Leader and Driver of Change in the Arab Gulf Region and Beyond. Enhancing Qatar's status as a leader and driver of Gulf-region change arose from several participant interviews and analysis of documents, including of U.S. and Qatar government and nongovernment reports. Interviewees, especially QF and Qatar representatives, referred to past Arab cultural and scientific contributions and framed branch-campus development as a renaissance. Participant L stated, "Education City is a center of renaissance"; Participant D stated that Qatar wants to revive "the Arab culture and civilization of the past. We want to enhance the image of Qatar as a regional center of excellence for learning"; and Blanchard (2010) quoted the U.S. Ambassador to Qatar: "I think of it as Qatar occupying a space in the middle of the ideological spectrum in the Islamic world, with the goal of having doors open to it across that ideological spectrum. They have the resources to accomplish that vision, and that's rare."

\section{Challenges}

My review of extant documents included annual reports and strategic and nonstrategic plans, did not provide meaningful or consistent insights into challenges encountered during early branch-campus operations; however, the following challenges emerged from my analysis of interviews with Qatar and branch-campus leadership.

Sociocultural Challenges. Many Qatari and branch-campus participants referred to sociocultural challenges, especially the need to bring parents and community on board with changes represented by both the American IBC model and Education City's coeducational environment. One Qatari participant said, "acceptance of change is perhaps the primary challenge. Change takes time and not all agree, particularly the conservatives" (Participant D). Qatari participants spoke about Qatari concern for the potential loss of Qatari culture and religion. They stressed IBC engagement with Qatari families and community as important 
to building trust and acceptance of change but stressed the need to maintain cultural and religious aspects within Education City. Participant P stressed that Education City should not become an "Island of Excellence" separated from society and that it should instead reach out to the community. Participant $\mathrm{R}$ affirmed that Education City must be "more integrated with the community." Participant Q explained that "our people have to feel that [Education City] is for them and for the good of the society."

Conflicting Expectations between the Branch Campuses and Qatar Foundation. Participants identified two main operation tensions between QF and branch campuses in the early years of operations: English proficiency and interIBC collaboration. First, student-English language proficiency was a significant issue at all six IBCs. Branch-campus leadership anticipated students' language proficiencies would be greater than they were: "The greatest challenge has been the English-language proficiency of the students. We were not aware that this problem was as pronounced as it actually is, in fact, it was a significant problem" (Participant F). Participant N, representing Qatari participants' view in general, stated, "Students had to spend too much time taking English, and some have been very angry. The issues and challenges needed to be rectified. There is a need for flexibility regarding culture and language." Both Qatar and IBC leadership stressed that this problem was primarily resolved after the first two years of operations.

Secondly, QF leadership wanted the six IBCs to collaborate, which the IBCs and IBC participants had not anticipated or understood. QF leadership envisioned campuses working together as a community towards academic enhancement, student flexibility, and common and engaging student experience. Participant A explained that "having separate and distinct institutions at Education City has been problematic [for us] each campus has been given the latitude to operate independently, so it is difficult to get them to work together" on issues like student engagement. According to Participant P, "a multiversity concept" was always a part of QF's plan; this requires the cooperation of all six branch campuses, and that is why we recruited peer universities - universities from the same country and with the same level of prestige." QF and IBC participants acknowledged that a compromise was eventually reached: "Her Highness really pushed the idea [of collaboration amongst IBCs]," and deans made concessions like cross-registration of courses and a joint convocation ceremony (Participant G).

Faculty-Recruitment Challenges. Branch-campus leadership spoke about the difficulting in recruiting faculty in the early days of operations. Several branchcampus participants explained that initial contractual agreements required recruitment of as many home-institution faculty as possible. Participant G explained that "the only interested faculty were part-time faculty and the young and therefore inexperienced - some directly out of graduate school." Participant L noted that "faculty for some specialized areas are [especially] difficult to recruit because of the research activities available at home." Because home institutions could not fulfill the agreement, compromises were reached. Participant K revealed 
that their branch campus had tried to secure two- and three-year faculty contracts but ultimately put in place eight-week contracts." Twenty-five percent of the current faculty members are from the home institution, coming on a rotational basis. Others are from various places around the world (Participant K).

Tensions between U.S. Parent Institutions and Qatar Branch Campuses. All branch-campus participants spoke of tensions between U.S. home institutions and Qatar IBCs during early operations, including lack of understanding of sociocultural realities faced by Qatar leadership; lack of trust and autonomy afforded by universities to IBCs; and difficulties of having two leadership bodies (i.e., one at home and one in Qatar). Participant V expressed "a lack of understanding by the home campus of the challenges, including institutional and cultural realities." Participant K stated, "we do not get enough support from the main campus." Participant $\mathrm{F}$ affirmed that past tensions existed "because the university did not understand the realities of the branch-campus environment." Participant T, from a more recently established IBC, stated, "we do not get enough support from the main campus, and they do not understand what happens here." Participant $\mathrm{G}$ emphasized that in the beginning years "the home university was less trusting of the branch campus than it is today" and that less autonomy was provided to the IBC. IBC participants who had been at their respective branch campuses for three or more years agreed that earlier problems with home institutions had largely been resolved.

\section{Discussion}

This study looks at Qatar's early rationales and goals for establishing an international branch-campus model of American universities in Qatar and the challenges encountered during the six IBCs' early years of operation from Qatar and branch-campus-leadership perspectives.

The five rationale and goal categories emergent from this study were 1) meeting Qatar's need for a quality higher education system that can foster critical thinking and system-wide reforms; 2) providing a quality educational experience from prestigious universities in Qatar and in a culturally appropriate environment; 3) preparing Qatar to participate in a global knowledge society by developing Qatar's human resources and research and development capacity; 4) facilitating engagement and sociocultural development of Qatari citizens; and 5) enhancing Qatar's status as a leader and driver of change in the Arab gulf region and beyond.

The four categories of challenges identified in this study were 1) sociocultural issues; 2) conflicting expectations between branch campuses and QF; 3) faculty recruitment; and 4) tensions between the American-based universities and their branch campuses in Qatar.

\section{Goals and Rationales}


Some of Qatar's rationales and goals for the American IBC higher-education model are consistent with the literature. Becker (2009), Lane (2011a), and Borgos (2016), similar to this study, found that host-country rationales and goals including building its higher education capacity and providing a quality education system within host countries. Consistent with this study, Borgos (2016) reported economy-tied rationales, including building local human-resource capacity, ability to participate in global markets, and the creation of a knowledge economy and a capacity for research (Crist 2015, 2017; Garrett, Kinser, Lane, \& Merola, 2017). This study found that Qatar's goal to build a knowledge society included building its research and development capacity with the help of six prestigious American research universities and their IBCs. In 2018, almost 10 years after this study, Qatar was forecasted to rank 29th in the world in terms of gross research and development expenditure (R\&D Magazine, 2018, p. 5).

With the exception of Kelly (2014), this study did not find connections between host-country rationales and sociocultural development and societal engagement in the literature, it found Qatar's rationales and aspirations for its American IBC model included desire for significant social changes, such as changing the culture of entitlement of some Qatari citizens, and facilitating a more open society with greater freedoms for women. While the IBC and Education City environments support a diverse student body and freedom of expression for all, additional research is needed to determine whether the endeavor has positively impacted areas outside Education City.

The literature references rationales and goals tied to enhancement of hostcountry prestige or reputation (Becker, 2009; Buckner 2011; Lane, 2011b); however, whether host countries provided this information is unclear, as is why host countries sought this prestige. In comparison, most participants in this study representing Qatar's perspective were clear that Qatar's early goals and rationales for the establishment of Education City and its American IBC model included an aspiration to be recognized as a leader in an Arab renaissance initiative. This renaissance initiative included making quality education more widely available in the Qatar region, broadening the country's research and development capacity, and developing an enlightened Arab knowledge model that encourages freedom of expression, creativity, critical thinking, problem-solving, and openness to other Arab cultures. Since this study, evidence has suggested that Qatar strove to connect meaningfully to the Arab world through QF and other domestic and international agencies, such as Qatar Foundation International. Such connection included supporting Arab languages and enhancing understanding of Arab societies and cultures through partnerships, research and development, and a greater focus on culture, arts, and heritage.

\section{Risks and Challenges}

While this study did not identify connections between host country Qatar and literature-identified IBC challenges and sociocultural development, it found some Qatar communities including families, were opposed to the American IBC model including the coeducational environments of the IBCs and extracurricular student 
opportunities, especially for women. Societal concerns also included the fear that aspects of Qatari culture and religion could be lost in the Education City environment, where more than $50 \%$ of students and faculty come from other cultures. QF and IBC strategies to engage and build trust and acceptance of Education City with Qatar families and communities mitigated the risk of lower enrolments as a result of IBC opposition. A review of American IBC-engagement activities in Qatar from 2016 to 2018 showed that initiatives, such as partnerships with public schools and community agencies, have been ongoing and have grown extensively since the early IBC operations (Appendix A).

While this study did not find reference to conflicting expectations between branch campuses and their host countries in the literature, it is likely that it exists. QF expected the six IBCs to collaborate on initiatives such as cross-registration of students among the campuses. IBCs were initially opposed to such collaboration. However, the leadership of each IBC worked cooperatively with the others, and $\mathrm{QF}$, to arrive at mutually agreeable solutions to these and other issues. Given QF's drive to build a multiversity environment within Education City, Qatar had the first such collaborative arrangement among distinct IBCs representing different universities.

Faculty-recruitment challenges found in this study were consistent with the literature. Altbach (2011), Healy (2016), and Smith (2014) reported difficulties with recruiting faculty from home institutions for extended periods, while Smith reported challenges with short-term faculty seconded from the parent institution. Most IBC participants in this study reported that short-term teaching assignments were a partial solution to recruitment challenges. Provision of research funding for IBC-based faculty and their domestic and international research partners was another solution to recruitment challenges. Qatar has made available significant research funding to U.S. branch campuses, other IBCs, Qatar University, and other Qatar education and research entities, allocating 2.8\% of its revenues to support research and development. A national survey compared Qatar 2012 and 2015 research expenditures in three sectors, including higher education. Within the higher-education sector, social-sciences expenditure saw the highest increase (57.9\%), followed by engineering and technology (17.8\%), and humanities (11\%; Government of Qatar, Ministry of Development Planning and Statistics, 2017, p. 21).

While the risk and reality of financial losses to home institutions that set up IBCs were prominent in the literature (Altbach, 2011; Becker, 2009; Borgos, 2016; Garrett et al., 2016; Wilkins, 2016), this study did not find such risk. QF financed the development and operation of the six American IBCs and did not require financial contributions from the parent universities. This arrangement positioned the American branch-campus model in Qatar uniquely, as compared with IBC arrangements elsewhere.

This study identified tensions between parent institutions and their branch campuses during the initial years of operation, a theme found in the literature (Healy, 2016; Hughes, 2011). Most IBC participants agreed that tensions lessened as home-university leadership familiarized itself with IBC issues and placed more trust in IBC leadership. 


\section{Conclusion}

This study examined Qatar's early goals and rationales for the establish-ment of an American branch campus model in partnership with six prestigious universities in the United States, and the early challenges encountered from the perspective of Qatar and the leadership of the branch campuses. Qatari participants were involved in the planning and development, oversight, and governance of the international branch campus model. Many of these participants worked closely with Qatar Foundation, a state-funded entity and home to Education City and the six IBCs.

Early challenges identified by participants included conflicting expectations between the IBCs and Qatar Foundation; faculty recruitment to the IBCs; and resistance to the American branch campus by individuals and groups in Qatari communities. Qatar Foundation and the branch campuses were willing to address challenges and find mutually acceptable solutions. Qatar's early goals and rationales include the desire to increase opportunities for quality university education for males and females; create an environment that fosters critical thinking, problem-solving, creativity, and freedom of expression; and develop the capacity for research. An overarching goal or aspiration of Qatar was to be recognized as a leader, in the region and beyond, in an Arab renaissance movement.

The six U.S. IBCs in Qatar were established between 2001 and 2008, and all were still in operation in January 2019. Given the longevity of the American international branch campuses in Qatar, there may be lessons for universities and host countries seeking to establish IBCs. Qatar's original goals for the American IBC model are ambitious; some would argue overly so. Further research is needed to determine the extent to which IBCs play a role in the realization of Qatar's goals.

\section{References}

Algonquin College. (2017, December 11). Approved board of governors meeting minutes. Retrieved from https://bit.ly/2CI4V2T.

Al-Misnad, Bint Nasser, \& M., Sheikha. (2004). Special Address [speech]. In United Nations Educational, Scientific and Cultural Organisation (Ed.), Final report of the meeting of higher education partners (World Conference on Higher Education), Paris, 23-25 June 2003 (pp. 80-83). Paris: UNESCO. Retrieved from https://bit.ly/2UhofxW.

Altbach, P.G. (2010). Why branch campuses may be unsustainable. International Higher Education, 58(2-3). Retrieved from https://bit.ly/2CL4fcW.

Altbach, P.G. (2011). Is there still a future for branch campuses? International Higher Education, 65(7-10). doi:10.6017/ihe.2011.65.8570.

Becker, R.F.J. (2009). International branch campuses: Markets and strategies. London: The Observatory on Borderless Higher Education. Retrieved from https://bit. ly/2HS6WOb. 
Blanchard, C.M. (2010). Qatar: Background and U.S. relations. Washington DC: Congressional Report Service, Library of Congress. Retrieved from https://bit. ly/2YHLRuP.

Borgos, J. (2016). Addressing sustainable international branch campus development through an organizational structure lens: A comparative analysis of China, Qatar, and the United Arab Emirates. Chinese Education and Society, 49(4-5), 271-287. doi:10.1080/10611932.2016.1237849.

Bowen, G.A. (2009). Document analysis as a qualitative research method. Qualitative Research Journal, 9(2), 27-40. doi:10.3316/QRJ0902027.

Buckner, E. (2011). The role of higher education in the Arab state and society: Historical legacies and recent reform patterns. The Journal of Comparative \& International Higher Education, 3, 21-26. Retrieved from https://bit.ly/2ODI50V.

Chapman, D., Austin, A., Farah, S., Wilson, E., \& Ridge, N. (2014). Academic staff in the UAE: Unsettled journey. Higher Education Policy, 27(1), 131-151. doi:10.10 57/hep.2013.19.

Crist, J.T. (2015). Innovation in a small state: Qatar and the IBC cluster model of higher education. The Muslim World, 105, 93-115. Retrieved from https://bit.ly/ 2I5a9JA.

Crist, J.T. (2017) "A fever of research": Scientific journal article production and the emergence of a national research system in Qatar, 1980-2011. International Perspectives on Education and Society, 33, 227-248. doi:10.1108/S1479-36792 0170000033011

de Wit, H., \& Hunter, F. (2015). The future of internationalization of higher education in Europe. International Higher Education, 83, 2-3. Retrieved from https://bit.ly/ 2uE38ra.

Fagan, L. (2017, June 15). Algonquin College took \$6.2M hit on failed Saudi campus. CBC News. Retrieved from https://bit.ly/2UoZ6kX.

Garrett, R. (2018). International branch campuses: Success factors. International Higher Education, 93, 14-16. doi:10.6017/ihe.0.93.10417.

Garrett, R., Kinser, K., Lane, J. E., \& Merola, R. (2016). International branch campuses: Trends and developments, 2016. London: The Observatory on Borderless Higher Education and C-Bert. Retrieved from https://bit.ly/2HRN W26.

Garrett, R., Kinser, K., Lane, J. E., \& Merola, R. (2017). International branch campuses: Success factors of mature IBCs, 2017. London: The Observatory on Borderless Higher Education and C-Bert. Retrieved from https://bit.ly/2u CFawr.

Government of Qatar, General Secretariat for Development Planning. (2008). Qatar national vision 2030. Retrieved from https://bit.ly/2TK66EJ.

Government of Qatar, Ministry of Development Planning and Statistics. (2017). Education in Qatar: Statistical profile 2016. Retrieved from https://bit.ly/2qRy Die.

Government of Qatar, Ministry of Development Planning and Statistics. (2018). Monthly figures on total population. Retrieved from https://bit.ly/2JRhXku.

Hamad Bin Khalifa University. (n.d.). About Hamad Bin Khalifa University. Retrieved from https://bit.ly/2JRiB1o.

Healey, N. M. (2016). The challenges of leading an international branch campus: The 'lived experience' of in-country senior managers. Journal of Studies in International Education, 20(1), 61-78. doi:10.1177/1028315315602928.

Hughes, Rebecca (2011). Strategies for managing and leading an academic staff in multiple countries. New Directions for Higher Education, 155, 19-28.

Jureidini, J. (2014). Arab Gulf States: Recruitment of Asian workers. Retrieved from https://bit.ly/2TMZaqc.

Kelly, S. (2014). Recent gains and new opportunities for women's rights in the Gulf Arab States. The Solutions Journal, 5(3). Retrieved from https://bit.ly/2TPOkjv. 
Kinser, K., \& Lane, J.E. (2016). International branch campuses: Evolution of a phenomenon. International Higher Education, 85, 3-5. doi:10.6017/ihe.2016.85. 9232.

Knight, J., \& Liu, Q. (2017). Missing but needed: Research on transnational education. International Higher Education, 88, 15-16. doi:10.6017/ihe.2017.88.9686.

Lane, J. E. (2011a). Global expansion of international branch campuses: Managerial and leadership challenges. New Directions for Higher Education, 2011(155), 5-17. doi:10.1002/he.440.

Lane, J. E. (2011b). Importing private higher education: International branch campuses. Journal of Comparative Policy Analysis: Research and Practice, 13(4), 367-381. doi:10.1080/13876988.2011.583106.

Lane, J.E., \& Kinser, K. (2011). Reconsidering privatization in cross-border engagements: The sometimes public nature of private activity. Higher Education Policy, 24(2), 255-273. doi: 10.1057/hep.2011.2.

Mazzarol, T., Soutar, G.N., \& Seng, M.S.Y. (2003). The third wave: Future trends in international education. The International Journal for Educational Management, 17(3), 90-99. doi:10.1108/09513540310467778.

Middle East Institute. (n.d.). Qatar's regional ambitions and the new emir. Retrieved from https://bit.ly/2CN0mEh.

Mills, A. (2008, July 25). U.S. universities negotiate tricky terrain in the Middle East. The Chronicle of Higher Education, 54(46), A1, A17-A18.

Qatar Foundation (2011). Annual Report 2010-2011.

Qatar Foundation. (n.d.-a). Education City: A unique ecosystem of academic excellence. Retrieved from https://bit.ly/2U7JAuw.

Qatar Foundation. (n.d.-b). Mission [Mission Statement]. Retrieved from https://bit.ly/ $2 \mathrm{dvFns} 4$.

Qatar Ministry of Transport and Communications (n.d). Qatar Science and Technology Park Retrieved from https://bit.ly/2YOrwUO.

Qatar Population 2018. (2018, September 30). Retrieved from https://bit.ly/2wyx4Hh.

Qatar Science and Technology Park. (2018). About: Qatar Science and Technology Park. Retrieved from https://bit.ly/2UipE7v.

R\&D Magazine (2018, Winter). 2018 Global R\&D funding forecast. A Supplement to $R \& D$ Magazine. Retrieved from https://bit.ly/2BNw581.

Redden, E. (2017, June 6). Crisis in Qatar. Inside Higher Ed. Retrieved from https://bit. ly/2CQSh1v.

Sidra Medical Research Center. (2010). Message from Her Highness. Retrieved from https://bit.ly/2HRjDc4.

Smith, K. (2014). Exploring flying faculty teaching experiences: Motivations, challenges and opportunities. Studies in Higher Education, 39(1), 117-134. doi:10.1080/03075079.2011.646259.

Stasz, C., Eide, E.R., \& Martorell, F. (2007) Post-secondary education in Qatar: Employer demand, student choice, and options for policy. Santa Monica, CA: RAND Corporation. Retrieved from https://bit.ly/2U8YyQQ.

Toth, A. (1994). Qatar. In H. C. Chapin (Ed.), Persian Gulf states: Country studies (pp. 149-196). Lanham, MA: Bernan.

Walsh, P. (2011). Becoming a knowledge society: State of Qatar rationales for the importation of a North American branch campus model of higher education in Qatar (Doctoral dissertation). Retrieved from ProQuest Dissertations \& Theses database. (Order No. NR75484). 
Wilkins, S. (2016). Establishing international branch campuses: A framework for assessing opportunities and risks. Journal of Higher Education Policy and Management, 38(2), 167-182. doi:10.1080/1360080X.2016.1150547

Zahlan, R.S. (1979). The creation of Qatar. London, England: Croom Helm.

\section{Appendix A}

IBC News and Events, 2016-2018

Carnegie Mellon University Qatar. (2017, January 26). CMU-Q and Qatar armed forces sign memorandum of understanding. Retrieved from https://www.qatar. cmu.edu/news/qatar-armed-forces/.

Carnegie Mellon University Qatar. (2018, November 15). New CMU-Q Dean's Panel Series delves into challenges, opportunities in Qatar. Retrieved from https:// www.qatar.cmu.edu/news/deans-panel-series/.

Georgetown University in Qatar. (2018). Planet Georgetown. Retrieved from https:// www.qatar.georgetown.edu/campus-life/educational-enrichment/planet-georget own.

Northwestern University in Qatar. (2018). Symposium: The state of the internet and the digital future, September 25-26, 2018. Retrieved from https://www.qatar.north western.edu/news/events/conferences/internet-digital-future.html.

Texas A\&M University at Qatar. (2018, October 17). Texas A\&M at Qatar brings science and engineering to life in Qatar's schools. Retrieved from https://www. qatar.tamu.edu/news-and-events/news/2018/10/17/texas-a-and-m-at-qatar-bringsscience-and-engineering-to-life-in-qatar's-schools/.

Virginia Commonwealth University School of the Arts in Qatar. (2018, July 19). Five exhibitions are taking place around Qatar this summer featuring works by our alumni and faculty. Retrieved from http://www.qatar.vcu.edu/news/four-exhibi tionsare-taking-place-around-qatar-this-summer-featuring-works.

Weill Cornell Medicine - Qatar. (2018, September 25). WCM-Q hosts wellness course to tackle modern health challenges. Retrieved from http://qatar-weill.cornell.edu/ media-and-news/news/story/wcm-q-hosts-wellness-course-to-tackle-modern-heal thchallenges. 
